\title{
How Island Geography and Shape may Influence Species Rarity and Biodiversity Loss in a Relict Fauna: A Case Study of Mediterranean Bee- tles
}

\author{
Simone Fattorini*
}

\author{
Dipartimento di Biologia Animale e dell'Uomo (Zoologia), Università di Roma “La Sapienza”, Viale dell'Università \\ 32, I-00185 Roma, Italy
}

\begin{abstract}
In accordance with their relictual character, the tenebrionid communities of the Aegean Islands appear scarcely affected by present geographic characteristics. Three measures of rarity at community level were calculated: geographic distribution, habitat exploitation, and population size. Islands with greater habitat diversity and size are those with higher values of distributional rarity. Island shape appears to be correlated with habitat exploitation and population size rarities: the communities with highest proportions of ecologically specialized and scarce species are associated with islands with lower perimeter/area ratios (which possibly lack extensive 'inner' habitats, like forests), while an elongate island shape exerts a positive influence on the incidence of species with small populations (possibly because of an increasing habitat diversity in elongate areas which may support $K$-selected species). On the whole, islands with a more elongated shape are those with the most vulnerable species. A paleogeographical and paleoecological model is proposed to explain present patterns of rarity. As a result of relaxation after saturation, remote small islands retained generally the most common (less vulnerable) species, rare species surviving mostly on the larger islands, although ecologically specialized species can be concentrated on some small islands, if these species are associated with peculiar but locally common habitats. The multidimensional representation of community rarity presented in this study provided important insights into our understanding of the biogeographic mechanisms which may be involved in biodiversity loss.
\end{abstract}

Keywords: Species rarity, Coleoptera Tenebrionidae, Aegean Islands, Greece, extinction.

\section{INTRODUCTION}

An astonishing large fraction of documented extinctions have involved species living on islands (e.g. [1,2]). As a rule, island populations are more prone to extinction than mainland ones, with island endemics having higher extinction rates than non endemics do $[3,4]$.

Islands are considered intrinsically more fragile than mainland areas (e.g. [5-7]) as a consequence of higher demographic stochasticity, random climatic events, and anthropogenic disturbance, such as species introduction, habitat changes and overexploitation (e.g. [2,8]).

Although the study of the species-area relationship, developed in the framework of island biogeography, has been used successfully to predict extinction rates following habitat loss (e.g. $[9,10]$ ), the influence of other island characteristics on species extinction has received less attention. According to the equilibrium theory proposed by MacArhtur and Wilson [11], larger islands harbour larger populations, which are less prone to extinction than the small populations living on smaller islands. As a consequence of reduced extinction rates, larger islands have more species. This model, however, applies only to equilibrial islands, where extinctions are balanced by immigrations [12], and the mean number of species remains stable, although species composition changes through time. Thus this model deals with species substitu-

*Address correspondence to this author at Via R.Ciasca, 78 I-00155, Roma, Italy; E-mail: simone_fattorini@ virgilio.it tions, while biodiversity loss is determined by species extinction not compensated by species immigration. The study of the influence of island characteristics on the loss of biodiversity may give important insights into our understanding of why islands are so strongly subject to biodiversity decline, and may provide important information for conservation purposes. This research aimed to investigate if species extinctions can be related to island geography in order to study which physical factors may determine greater community fragility and hence higher risk of biodiversity decline in a relict fauna.

\section{MATERIALS AND METHODS}

\section{Study Area and Data Sources}

The Mediterranean Basin is an important biodiversity hotspot and its islands are of special conservation concern (e.g. $[5,13])$. The great majority of Mediterranean island faunal diversity is composed of invertebrates, yet, the knowledge of insect conservation in Mediterranean type ecosystems is at its beginning. For such reasons I attempted here an analysis focused on an insect group in the Aegean archipelago (Fig. 1), one of the most complex and important Mediterranean insular system (e.g. [13-16]).

Phrygana is the dominant vegetation type throughout the islands, while oak forest (which is considered the climax vegetation) and maquis habitats occur only in scattered patches on some of the largest islands. Although pre-Minoan Crete had significantly more woodland than it does today, remains of plants typical of phrygana and maquis are found 
in interstadials of the last glaciation [17]. I chose tenebrionids (Coleoptera Tenebrionidae) as a case study for several reasons. Tenebrionids are an important group in the structure and functioning of Mediterranean insular biotas [18]. The importance of the tenebrionid beetles of the Aegean Islands from a conservation standpoint is enhanced by their acknowledged importance in determining endemicity hotspots $[15,19,20]$. Lastly, the tenebrionid fauna of the Aegean Islands has been taxonomically and faunistically revised recently and distributional data can be considered fairly complete and accurate [21-24]. In total, 32 islands were included in this study (Fig. 1, Appendix S1). On the Aegean Islands, several tenebrionid species are represented by different subspecies endemic to individual islands or groups of islands, suggesting that patterns of tenebrionid distribution and diversity in the archipelago are established over evolutionary time. These populations can thus be recognized as evolutionarily significant units and I have counted them as different taxa (cf. [21-25] for details about the treatment of subspecies).

As a whole, 162 taxa (130 species and 32 subspecies) were considered in this study. The term 'species' will be used in reference to tenebrionid taxa for simplicity. Taxonomic treatment and data concerning species distribution among islands are the same as in Fattorini [26,27]. For temporal analyses, I referred to collection dates gathered by Fattorini [19,26], which ranged from 1870 to 2000. Raw data are provided in Appendix S2 and S3.

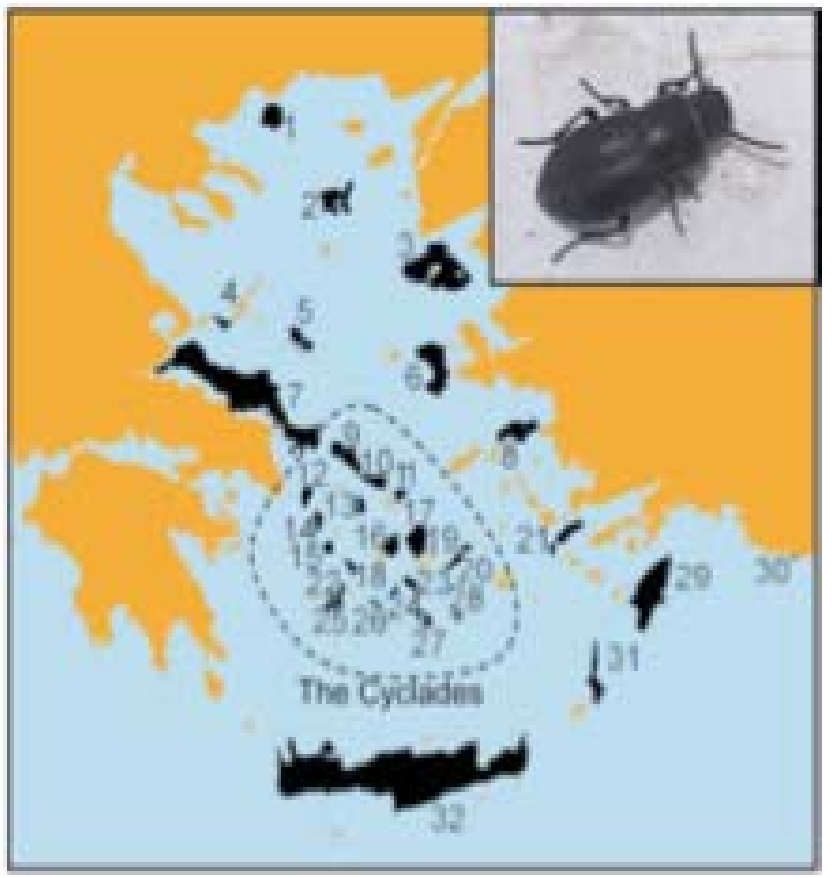

Fig. (1). Map of the study area. Studied islands are in black. Alternative names are in brackets. 1: Thasos, 2: Lemnos, 3: Lesvos (=Lesbos), 4: Skopelos, 5: Skiros, 6: Chios, 7: Euboea(=Evvoia), 8: Samos, 9: Andros, 10: Tinos, 11: Mikonos, 12: Kea, 13: Siros, 14: Kithnos, 15: Serifos, 16: Paros, 17: Naxos, 18: Sifnos, 19: Pano Koufonissi, 20: Amorgos, 21: Kos, 22: Kimolos, 23: Ios, 24: Sikinos, 25: Milos, 26: Folegandros, 27: Santorin (=Santorini, Thira), 28: Anafi, 29: Rhodos (=Rhodes), 30: Castellorizo (=Kastellorizo, Meghisti), 31: Karpathos, 32: Kriti (=Crete). Inset: Dailognatha hellenica from Santorini.

\section{Species Rarity and Vulnerability}

I used three dimensions of species rarity as defined and calculated in a companion paper ([25] see this paper for details about the rationale, applicability, and limitations of each of the following measures):

\section{Geographic Distribution ( $\psi$ )}

I estimated the geographic range of a species in the study area as the number of islands from which the species is known in proportion to the total number of islands. This index, termed $\psi$ after Dennis et al. [28], allows for an estimation of species rarity on the basis of the geographic distribution within the study area.

\section{Habitat Exploitation ( $(\varepsilon)$}

It is well known that larger areas tend to have a great variety of habitats and that habitat heterogeneity increases with area. Thus, the extent of the area occupied by a species may be considered a rough proxy for its ecological tolerance or, at least, a measure of its potential habitat exploitation. For each species, I calculated the maximum potential 'area of occupancy' as the sum of the areas of the individual islands inhabited within the archipelago. This value was then divided by the sum of the individual areas of all islands considered in the study, and this measure of potential habitat exploitation was considered an index of ecological tolerance.

\section{Local Population Size (Density) (ס)}

Since no quantitative data were available, local population size was estimated by species 'contactability', because encounter rates are proportional to population density. To assess species contactability, I subdivided species records into decades, from 1870 to 2000 . Species contactability was estimated as the proportion between the number of decades from which records of a given species were available and the total number of decades until extinction is assumed (last decade with records). A species was assumed as continuously present from 1870 to the last decade of occurrence, even if not recorded in certain decades within this range.

\section{Vulnerability Index (v)}

Species with smaller ranges, lower abundances and narrower ecological tolerances tend to experience higher levels of threat (e.g. [29]). Thus, the different measures of rarity can be combined to obtain an index of vulnerability. Using $\psi, \delta$ and $\varepsilon$ measures of rarity, I calculated an index of species vulnerability ( $\mathrm{v}$ ) applying the method proposed by Kattan [30]. If species are dichotomized for each of these variables, an eight-celled model is created that reflects different types of rarity and commonness. Kattan [30] proposed assigning to each cell a number between 1 (species 'rare' in three dimensions) and 8 (species 'common' in three dimensions) to indicate susceptibility to extinction. For each dimension (measure) I dichotomized species into two groups (common and rare) according to whether they were above or below the median and then I assigned each species to a cell as proposed by Kattan. The median values were: 0.0313 for geographic distribution, 0.185 for habitat exploitation, and 0.279 for density. For each dimension, rare species were those below the median value [30]. Note that all these indices of rarity increase as species became less rare. 


\section{Community Rarity and Vulnerability}

The aforementioned indices were used as species parameters to construct rarity indices at community level (see [26]).

\section{Distributional Rarity ( $(\boldsymbol{)})$}

Each island was scored according to a rarity index $(\Psi)$ as proposed by Dennis et al. [28]:

$\Psi=1-\left[\left(\sum_{\mathrm{i}=1, \mathrm{j}} \psi_{\mathrm{i}}\right) / S_{\mathrm{j}}\right]$

where $\psi_{\mathrm{i}}=n_{\mathrm{i}} / N$, for $\mathrm{i} \ldots \mathrm{j}$ species, $S$, and $\mathrm{n} \leq N$ islands.

This index is a measure of mean incidence of species on islands in the archipelago, with high values indicative of increasing mean rarity of an island's fauna and low values of ubiquity of species comprising an island's fauna.

\section{Habitat Exploitation Rarity (E)}

For each island, an index of habitat exploitation rarity was calculated as follows:

$\mathrm{E}=1-\left[\left(\Sigma_{\mathrm{i}=1, \mathrm{j}} \varepsilon_{\mathrm{i}}\right) / S_{\mathrm{j}}\right]$

where $\varepsilon_{i}$ is the index of habitat exploitation discussed above and $S$ is the species richness of an island. This index is a measure of mean habitat selectivity of species on islands in the archipelago, with high values indicative of increasing ecological specialization of an island's fauna. For simplicity, this index will be referred to as 'habitat rarity'.

\section{Population Size Rarity (4)}

For each island, an index of abundance was calculated as follows:

$\Delta=1-\left[\left(\Sigma_{\mathrm{i}=1, \mathrm{j}} \delta_{\mathrm{i}}\right) / S_{\mathrm{j}}\right]$

where $\delta_{\mathrm{i}}$ is the index of species contactability discussed above and $S$ is the species richness of an island. Large values indicate concentration of species with small population size.

\section{Vulnerability $(K)$}

For each island, I calculated a relative index of vulnerability as follows:

$\mathrm{K}=1-\left[\left(\sum_{\mathrm{i}=1, \mathrm{j}} \mathrm{v}_{\mathrm{i}}\right) / \mathrm{K}_{\mathrm{Max}}\right]$

where $\mathrm{v}_{\mathrm{i}}$ is the index of species vulnerability discussed above and $\mathrm{K}_{\mathrm{Max}}$ is the theoretical maximum (all species occurring on a given island with $v=8$ ). High values indicate high vulnerability.

\section{Effects of Island Physical Characteristics}

To study possible relationships between the aforementioned indices and island characteristics, I used forward stepwise multiple regression analyses [31,32]. I considered the following eco-geographic parameters currently used in island biogeography: area, elevation, island perimeter, distance to the mainland, and distance to the nearest island (Appendix S1). Elevation was considered a measure of habitat diversity [31]. All geographic variables were $\log _{10^{-}}$ transformed to improve normality and reduce heteroscedasticity. I also used some indices of shape widely applied in landscape ecology [33]: Perimeter-Area Ratio (PARA= P/A, where $\mathrm{P}=$ perimeter, and $\mathrm{A}=$ area), Corrected Perimeter-Area Ratio $(\mathrm{CPA}=(0.282 \times \mathrm{P}) / \sqrt{ } \mathrm{A})$, Related Circumscribing Circle $\left(\mathrm{RCC}=\left(2 \times(\mathrm{A} / \pi)^{1 / 2}\right) /\right.$ longest-axis $)$, and Fractal Dimen- sion $(\mathrm{FD}=2 \log \mathrm{P} / \log \mathrm{A})$ (Appendix $\mathrm{S} 1)$. Although $\mathrm{FD}$ and PARA deviate from normality, I did not apply transformations to do not mathematically change their primitive significance. I preferred to consider geographic and island shape variables as two separate sets, for both logical and statistical reasons. Some geographic parameters may be statistically tightly correlated to some shape measures, but have different meanings. Strict correlations among the two sets of variables could cause multicolinearity problems in applying stepwise multiple regressions and the importance of a variable of a set could be obscured by a variable of the other set which is tightly correlated but has a different ecological significance. Finally, spatial variables, which can incorporate the effects of otherwise ignored historical, biotic, or environmental variables, were considered. The third-degree polynomial of latitude and longitude (expressed as UTM coordinates in meters) were used as independent variables for a trend surface analysis [34]. The package SpaceMaker2 [35] was used to obtain the spatial descriptor terms required for the polynomial trend surface regression. Backward stepwise regressions ( $F$ to remove set at 4 , intercept set at zero) with the nine terms of the third-degree polynomial as predictor variables and each index of rarity as dependent variable were carried out to remove the non-significant $(p>0.05)$ spatial terms [36]). Forward stepwise multiple regressions have been used for ranking the geographic and shape variables, as well as the spatial terms which were retained from the backward procedure, according to their importance to determine $\Psi, \mathrm{E}, \Delta$, and $\mathrm{V}$ indices following the statistical procedures described in Fattorini [23]. Statistical analyses were performed with the Statistica v.6.0 package [37]. For each index, a rarity landscape was constructed using bi- and threedimensional mesh plots of index values (vertical axis) against geographic coordinates (expressed in decimal degrees) using the utilities of SigmaPlot v.10.0 [38]. Note that because of the uneven distribution of islands in the geographic space, interpolation in some geographic sectors with no islands can be biased by the values recorded for the nearest islands.

\section{Extinction Analyses}

To calculate the incidence of species extinctions on islands, I compared species occurrences in two time intervals pivoting upon 1960. Species no longer recorded on a given island after 1960 were considered here extinct. I used the year 1960 as pivotal date because the influence of mankind on flora and fauna in Greece, notably on the islands, has never been as strong as during the last forty years (see [25] for details). For each island I calculated the number and percentage of species no longer recovered since 1960 (percentage of extinct species) as measures of species extinction. Then, I studied the influence of the aforementioned geographic and shape parameters on the number of extinct species and the arcsintransformed values of the percentage of extinct species by both pairwise correlations and forward stepwise multiple regressions. To study if extinctions are related to community rarity and vulnerability, I used the Pearson coefficient on arcisntransformed percentages and numbers of extinct species. 14 islands were omitted because they are suspected to be disproportionally undersampled (no species recorded after 1960). In all aforementioned tests a minimum probability level of $p<0.05$ was accepted (all tests 
Table 1. Rarity Indices of Tenebrionid Communities on the Aegean Islands

\begin{tabular}{|c|c|c|c|c|c|c|}
\hline & $\mathbf{L a}$ & Lo & $\Psi$ & $\mathbf{E}$ & $\Delta$ & $\mathbf{K}$ \\
\hline Amorgos & 36.83 & 25.93 & 0.580 & 0.653 & 0.560 & 0.143 \\
\hline Anafi & 36.35 & 25.83 & 0.690 & 0.623 & 0.577 & 0.198 \\
\hline Andros & 37.75 & 24.70 & 0.638 & 0.642 & 0.540 & 0.156 \\
\hline Castellorizo & 36.13 & 29.57 & 0.769 & 0.675 & 0.646 & 0.312 \\
\hline Chios & 38.37 & 26.00 & 0.662 & 0.543 & 0.508 & 0.075 \\
\hline Euboea & 38.57 & 23.83 & 0.854 & 0.645 & 0.577 & 0.366 \\
\hline Folegandros & 36.62 & 24.90 & 0.576 & 0.604 & 0.571 & 0.179 \\
\hline Ios & 36.70 & 25.40 & 0.573 & 0.686 & 0.564 & 0.111 \\
\hline Karpathos & 35.67 & 27.17 & 0.781 & 0.616 & 0.619 & 0.134 \\
\hline Kea & 37.57 & 24.37 & 0.651 & 0.684 & 0.519 & 0.167 \\
\hline Kimolos & 36.80 & 24.57 & 0.510 & 0.575 & 0.462 & 0.083 \\
\hline Kithnos & 37.42 & 24.47 & 0.453 & 0.573 & 0.500 & 0.062 \\
\hline Kos & 36.83 & 27.17 & 0.751 & 0.590 & 0.604 & 0.144 \\
\hline Kriti & 35.48 & 24.70 & 0.885 & 0.510 & 0.682 & 0.284 \\
\hline Lemnos & 39.90 & 25.35 & 0.656 & 0.557 & 0.519 & 0.087 \\
\hline Lesvos & 39.17 & 26.33 & 0.667 & 0.492 & 0.501 & 0.110 \\
\hline Mikonos & 37.48 & 25.42 & 0.631 & 0.683 & 0.535 & 0.150 \\
\hline Milos & 36.68 & 24.25 & 0.613 & 0.521 & 0.523 & 0.076 \\
\hline Naxos & 37.03 & 25.58 & 0.721 & 0.593 & 0.585 & 0.118 \\
\hline Pano Koufonissi & 36.93 & 25.98 & 0.630 & 0.610 & 0.558 & 0.125 \\
\hline Paros & 37.13 & 25.20 & 0.597 & 0.708 & 0.577 & 0.125 \\
\hline Rhodos & 36.17 & 28.00 & 0.826 & 0.645 & 0.679 & 0.300 \\
\hline Samos & 37.80 & 26.73 & 0.708 & 0.662 & 0.505 & 0.277 \\
\hline Santorin & 36.40 & 25.48 & 0.726 & 0.561 & 0.592 & 0.115 \\
\hline Serifos & 37.18 & 24.52 & 0.613 & 0.445 & 0.500 & 0.062 \\
\hline Sifnos & 36.98 & 24.67 & 0.583 & 0.529 & 0.504 & 0.056 \\
\hline Sikinos & 36.65 & 25.10 & 0.625 & 0.686 & 0.591 & 0.141 \\
\hline Siros & 37.43 & 24.90 & 0.698 & 0.640 & 0.562 & 0.141 \\
\hline Skiros & 38.88 & 24.53 & 0.679 & 0.693 & 0.628 & 0.216 \\
\hline Skopelos & 39.17 & 23.67 & 0.803 & 0.756 & 0.584 & 0.214 \\
\hline Thasos & 40.68 & 24.78 & 0.799 & 0.693 & 0.661 & 0.283 \\
\hline Tinos & 37.63 & 25.17 & 0.664 & 0.696 & 0.433 & 0.229 \\
\hline
\end{tabular}

$\mathrm{La}=$ latitude (decimal degrees), $\mathrm{Lo}=$ longitude (decimal degrees), $\Psi=$ geographic rarity, $\mathrm{E}=$ habitat rarity, $\Delta=$ population rarity, $\mathrm{K}=\mathrm{Kattan}$ index of vulnerability.

were two-tailed). In accordance with the suggestions of Moran [39], I did not apply any adjustment of significant levels, but focused on $p$-values and consistence of results.

\section{RESULTS}

\section{Community Rarity and Vulnerability}

Indices of community rarity and vulnerability are reported in Table 1. Significant correlation was found between geographic rarity and population rarity, while habitat exploitation rarity was not correlated with other measures of tation rarity was not correlated with other measures of rarity (Table 2).

Kattan index was correlated with all measures of rarity, while number and percentage of extinct species were not correlated with rarity indices.

4.

Results of multiple regressions are reported in Tables 3 - 
Table 2. Pearson Correlation Coefficients Between Rarity Indices, Kattan Vulnerability Index, and Number of Extinct Species

\begin{tabular}{|c|c|c|c|c|c|}
\hline & $\mathbf{E}$ & $\boldsymbol{\Delta}$ & $\mathbf{K}$ & Ext Ext & 0.369 \\
\hline \hline$\Psi$ & 0.155 & $0.676^{* * *}$ & $0.734^{* * *}$ & -0.007 & -0.178 \\
\hline $\mathrm{E}$ & & 0.251 & $0.487^{* *}$ & 0.110 & -0.315 \\
\hline$\Delta$ & & & $0.540^{* * *}$ & 0.248 & -0.004 \\
\hline $\mathrm{K}$ & & & & 0.4 \\
\hline
\end{tabular}

$\Psi=$ geographic rarity, E= habitat rarity, $\Delta=$ population rarity, $\mathrm{K}=$ Kattan index of vulnerability, Ext= number of extinct species, \%Ext= percentage of extinct species (arcsintransformed), ** $p<0.01, * * * p<0.001$.

Table 3. Results of Forward Stepwise Regression Analyses for the Relationships Between Rarity Indices and Island Geography

\begin{tabular}{|c|c|c|c|c|c|}
\hline & \multicolumn{4}{|c|}{ Standardized coefficients $( \pm S E)$} & Model statistics \\
\hline & $\log \mathbf{A}$ & $\operatorname{logEI}$ & $\mathbf{L o}^{3}$ & $\mathbf{L a}^{2}$ & \\
\hline \hline$\Psi$ & & $0.458 \pm 0.120$ & $0.472 \pm 0.116$ & $0.282 \pm 0.120$ & $\mathrm{R}_{\text {adj }}^{2}=0.589, F(3,28)=15.810 p<0.0001$ \\
\hline $\mathrm{E}$ & & & & & $\mathrm{R}_{\text {adj }}^{2}=0.175, F(5,26)=2.312 p=0.073$ \\
\hline $\mathrm{K}$ & & & & $0.398 \pm 0.164$ & $\mathrm{R}_{\text {adj }}^{2}=0.185, F(2,29)=4.528 p<0.05$ \\
\hline Ext & $0.212 \pm 0.579^{*}$ & & $0.435 \pm 0.183$ & & $\mathrm{R}_{\text {adj }}^{2}=0.424, F(6,25)=4.796 p<0.01$ \\
\hline$\%$ Ext & & & & & $\mathrm{R}_{\text {adj }}^{2}=0.316, F(2,15)=4.925 p<0.05$ \\
\hline
\end{tabular}

Only standardized coefficients $( \pm S E)$ for significant variables $(p<0.05)$ are shown. Degrees of freedom take into account all explanatory variables retained by the stepwise procedure, including those not shown (non-significant variables). $\log \mathrm{A}=$ area $\left(\log\right.$-transformed), $\log \mathrm{El}=$ elevation $\left(\log\right.$-transformed), $\mathrm{Lo}^{3}=\mathrm{cubic}$ term of $\operatorname{longitude}, \mathrm{La}{ }^{2}=$ quadratic term of Latitude, $\Psi=$ geographic rarity, $\mathrm{E}=$ habitat rarity, $\Delta=$ population rarity, $\mathrm{K}=$ Kattan index of vulnerability, Ext= number of extinct species, \%Ext= percentage of extinct species (arcsintransformed), $\mathrm{R}_{\text {adj }}^{2}=$ Adjusted $\mathrm{R}^{2}$ statistic. $*$ =probability level slightly superior to $p=0.05$. Note that regressions for $\mathrm{E}$ and $\%$ Ext are not significant.

Pairwise comparisons by the Pearson product moment correlation coefficient suggested positive dependence of $\Psi$ on area $(r=0.502, p<0.01)$, elevation $(r=0.557, p<0.001)$ and perimeter $(r=0.426, p<0.05)$, whilst distance to the mainland correlated negatively $(r=-0.479, p<0.01)$. However, multiple regression analyses showed that $\Psi$ index was positively influenced by elevation alone.

The only parameter which affected $\mathrm{E}$ was (negatively) CPA $(r=-0.383, p<0.05)$. No variable affected significantly the $\Delta$ index by pairwise correlations, whilst negative correlations were found with RCC and CPA in multiple regression.
K was positively correlated with elevation $(r=0.379$, $p<0.05)$ and negatively with distance to mainland $(r=-0.580$, $p<0.01)$. These correlations were not recovered by multiple regressions, which found negative correlations with RCC and CPA.

Rarity indices were spatially structured. Some spatial terms (namely $\mathrm{Lo}^{2}, \mathrm{La}^{2}, \mathrm{Lo}^{3}$ ) were retained from backward stepwise regressions for $\Psi, \mathrm{E}$, and $\Delta$.

When included in forward stepwise regressions, $\mathrm{La}^{2}$ and $\mathrm{Lo}^{3}$ exerted a significant influence on $\Psi$ and $\mathrm{K}$ indices, while $\mathrm{La}^{2}$ on $\Delta$ index.

Table 4. Results of Forward Stepwise Regression Analyses for the Relationships Between Rarity Indices and Island Shape

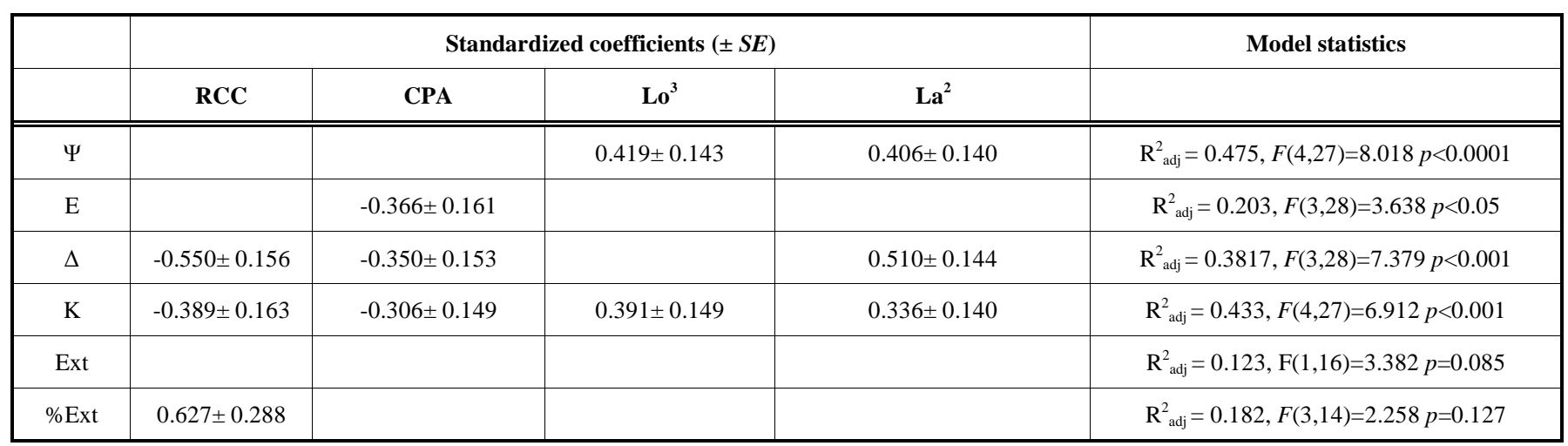

Only standardized coefficients $( \pm S E)$ for significant variables $(p<0.05)$ are shown. Degrees of freedom take into account all explanatory variables retained by the stepwise procedure, including those not shown (non-significant variables). RCC $=$ Related Circumscribing Circle, $\mathrm{CPA}=$ Corrected Perimeter-Area Ratio, $\mathrm{Lo}^{3}=\mathrm{cubic}$ term of longitude, $\mathrm{La}^{2}=$ quadratic term of Latitude, $\Psi=$ geographic rarity, E= habitat rarity, $\Delta=$ population rarity, K= Kattan index of vulnerability, Ext= number of extinct species, \%Ext= percentage of extinct species (arcsin-transformed), $\mathrm{R}_{\text {adj }}^{2}=$ Adjusted $\mathrm{R}^{2}$ statistic. Note that regressions for Ext and \% Ext are not significant. 
Three-dimensional representations of spatial variations showed for all indices a distinct geographic structure, with sharp decreases along the line that separates the Balkan islands (which were connected or closer to the Balkan peninsula during the Ice Age) from the Anatolian ones (which in the Ice Age were connected to the Anatolian peninsula) (Fig. 2). Generally speaking rarity peaks were concentrated on Crete, Euboea and some of the Cyclades. In particular, geographic rarity assumed high values for Euboea and the South Aegean Arch (Crete, Rhodos and Karpathos). Habitat exploitation rarity was diffused on some Cyclades, northern islands and south-eastern islands, attaining low values on most of the Cyclades. Population rarity was very high on some of the largest islands and on the South Aegean Arch. Finally, the Kattan index identified two main sectors of rarity: a northwestern sector and a south-western one, with a central valley of low rarity.

\section{Extinction Analyses}

Forward stepwise multiple regressions showed a positive influence of area on the number of extinct species (Tables 34). No other significant relationships were found. Pairwise significantly positive correlations were found between number of extinct species and area $(r=0.586, p<0.05)$, elevation $(r=0.470, p<0.05)$ and perimeter $(r=0.568, p<0.05)$. No significant pairwise correlation was found between proportions of extinct species and geographic or shape variables.

\section{DISCUSSION}

\section{Factors Affecting Community Richness, Rarity, and Vul- nerability}

The most important predictors of tenebrionid species richness in the Aegean archipelago are area and habitat diversity, thus suggesting that both area per se and habitat diversity mechanisms are in effect [33]. Several lines of evidence (e.g. lack of relationship between species richness and distance to the mainland, as well as biogeographic relationships among islands) show that the Aegean tenebrionids are a relict fauna $[33,40,41]$. Relict models postulate that present distribution patterns of insular faunas are more dependent on historical factors (like the paleogeographic connections between islands and mainland areas followed by vicariance events) than present conditions (like island distance to the mainland). Spatial patterns of variations in the tenebrionid rarity on the Aegean Islands support this model [26] and this study provides insights into the possible underlying mechanisms. At community level, distributional rarity was positively affected by elevation, suggesting that a greater habitat heterogeneity may determine the occurrence of species which have narrow distributions because they are associated with rare habitats occurring only on the islands with highest habitat diversity. However, as area and elevation are strongly interrelated, this relationship may actually be a reflection of an increasing geographic rarity with increasing area. Islands with larger areas could tend to concentrate rare species possibly because of at least two (not mutually exclusive) reasons: (1) larger islands have more species and, hence, more 'rare species' simply because they are a subsample of the total richness (as demonstrated for the Aegean butterflies, where the number of geographically rare species and that of imperilled species were strictly correlated with species richness [16]); and (2) larger islands are ecologically more var- ied, thus harbouring species with narrow distribution because they are ecologically restricted to rare habitats which can occur only on large islands.

Habitat rarity is negatively affected by large perimeterarea ratio values (CPA). Islands with large CPA values are likely to have long coasts but a small 'core' area. Thus we suppose that these islands likely lack those 'inner' habitats (such as forests) which could be essential for some ecologically specialized species.

Population rarity increased with increasing elongation in island shape (inverse correlation with island roundness, RCC). Even though some authors attempted to derive some recommendations about refuge shape from island biogeography theory, the importance of island shape on species diversity has been rarely investigated. However, as a general rule, island shape does not appear to have a substantial role in determining species richness (see [33] and references therein). If anything, available data indicate that there is a slight tendency for elongate islands to have more species than rounded ones do. In particular, for the Aegean area, Simberloff [42] found that the bird richness on the Cyclades is slightly enhanced by elongate shape. Likewise, in contrast with the idea that round shape is preferable for refuges, Aegean tenebrionid richness appeared slightly increased by an elongate island shape [33]. The actual reason why elongation may enhance diversity is difficult to establish, although increasing habitat diversity in elongate areas has been evoked [42]. However, these studies dealt with species richness, not with species vulnerability or ecological characteristics. Results presented here show that a more elongate shape may actually determine an increase in species with small populations. On the other hand, population size rarity is decreased by large perimeter-area ratio values (CPA). It can be postulated that islands with large CPA values are characterized by most prominent edge effects which could favour $r$-selected species, thus decreasing the number of $K$-selected species (which are thought to have small populations). Edge environments could be characterized by more instable or severe conditions that favour species with large populations. For example, coastal environments (which cover larger areas on more elongate islands with large CPA values) are mostly inhabited by $r$-selected species with large populations [18].

Finally, vulnerability index decreased in remote islands (which have also smaller areas: distance to mainland $v s$ area: $r=-0.356, p<0.05)$ and increased in the highest ones. In equilibrial archipelagos, large islands may act as sources for small and remote islands or can assist species which come from the mainland acting as stepping stones. However, the Aegean tenebrionid fauna is mostly relictual, and this mechanism cannot play a relevant role in determining the relationships between vulnerability and distance and between vulnerability and elevation/area. By contrast, a model of relaxation after saturation appears most probable as an explanation for these relationships. An analysis of the spatial variations of rarity (Fig. 2; see also [26]) shows that that geographic rarity increased from the centre of the archipelago to periphery. Islands located at very high or low latitude, which include some of the largest ones, have faunas with small population sizes, while habitat rarity appeared concentrated on small but clumped islands in the centre of the archipelago. Vulnerability index decreased in remote islands, 

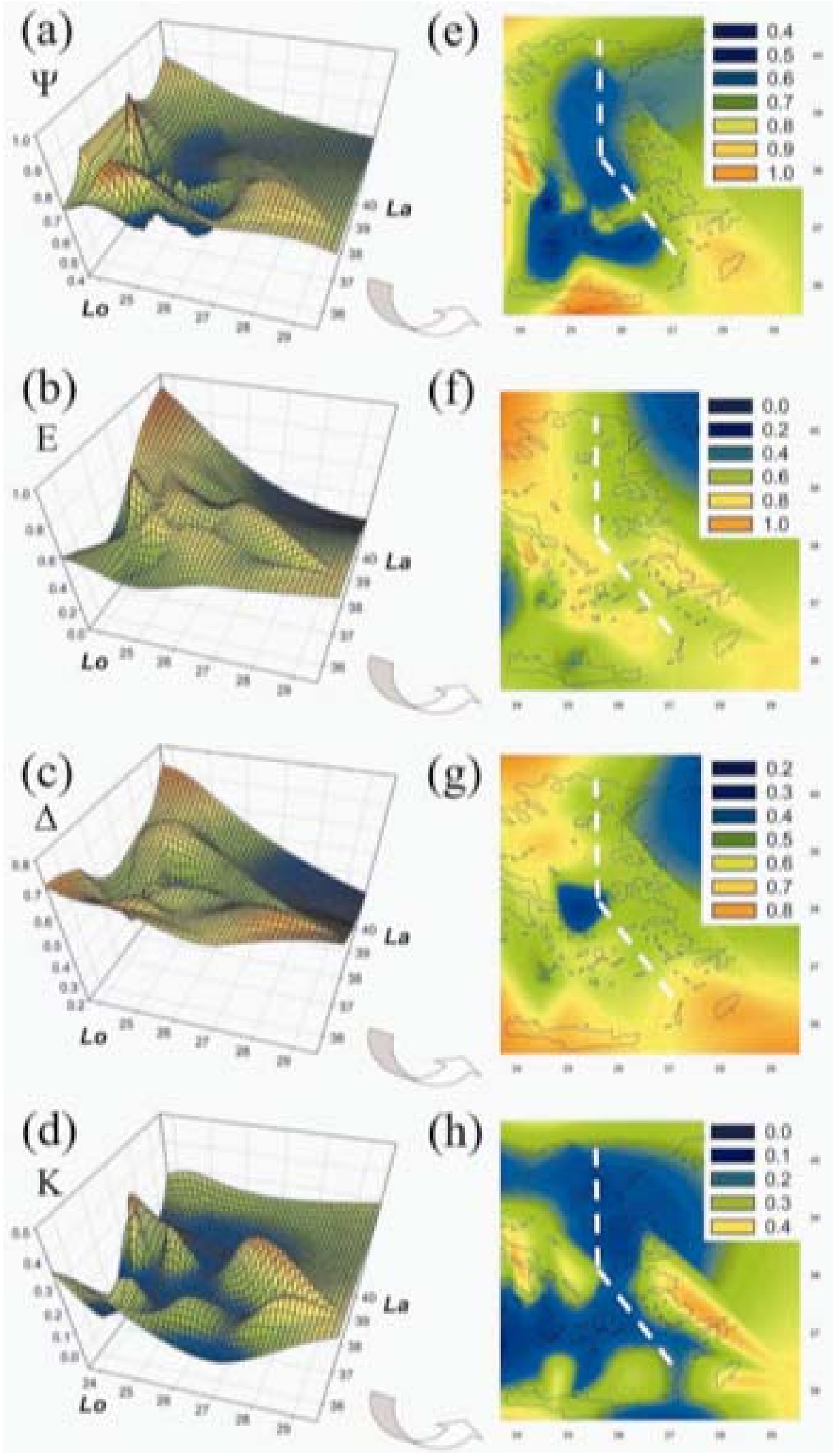

Fig. (2). Spatial variations in geographic rarity $(\psi)$, habitat rarity $(E)$, population rarity $(\Delta)$, and Kattan index of vulnerability (K) for the tenebrionid beetles of the Aegean Islands. Figs a-d are three-dimensional mesh plots, while Figs e-h are the respective bi-dimensional projections. $\mathrm{Lo}=$ Longitude, $\mathrm{La}=$ Latitude. The broken line indicates the biogeographic separation between the Balkan and the Anatolian islands (see [21$23,27,33])$. Note that because of the uneven distribution of islands in the geographic space, interpolation in some geographic sectors with no islands (notably the south-eastern corner and the northernmost sector) can be biased by the values recorded for the nearest islands. For ease of comparison, a diagrammatic map of the study area has been superimposed on bi-dimensional plots. 
which are usually also the smallest. Most of the Aegean remote islands were connected to each other and to the mainland during Pleistocene falls in sea level. Pleistocene island groupings may be considered as large paleoislands that were species-satured. When these groupings were again fragmented, the resulting islands retained only some of the species which composed the original fauna, a process known as relaxation, whilst major islands, as well as those which were connected to the mainland, were less affected by this phenomenon, being able to conserve a more complete fauna. During relaxation, species with small population size were presumably more affected by extinction, and the resulting fauna was mostly dominated by species with higher population density. Thus, remote small islands retained generally the most common (less vulnerable) species, rare species surviving mostly on the larger islands, although ecologically specialized species can be concentrated on some small islands, if they are associated with peculiar but locally common habitats (e.g. sand-dwelling species, which are highly specialized for a type of habitat which is common on small islands [18]). This model is also confirmed by the fact that endemic species or subspecies restricted to remote small islands actually belong to genera or species groups widely distributed in the archipelago (e.g. Dailognatha, Dendarus, Stenosis, Colpotus, etc.). It can be supposed that during Pleistocene regressions the ancestors of these taxa were largely distributed on the islands as common species. These ancestors survived relaxation, but, as a consequence of isolation, evolved in new taxa. This model may explain why the most restricted species/subspecies actually belong to widely distributed taxa.

As to the increasing vulnerability with elevation, it may be related to the fact that elevation is correlated with island area and expresses habitat heterogeneity [21,33]. Thus, islands with greater elevation possess faunas with greater vulnerability, possibly because these islands are those which were less affected by relaxation, retaining a larger number of specialized, restricted and less abundant (and therefore more vulnerable) species, which in contrast disappeared from other islands.

This historical reconstruction clearly shows how important are relict faunas because of their irreplaceability. In equilibrial faunas, locally extinct species can be replaced by new species. By contrast, in non-equilibrial faunas, communities are the result of ancient processes of colonization and speciation, so that extinct species cannot be replaced by new immigrants.

\section{Extinction Analyses}

A disproportionate percentage of tenebrionid species loss during the last 50 years has occurred on the Aegean Islands. Although some species could be erroneously considered as being extinct because of lack of research, the emerging patterns clearly show an impressive decline, especially during the last years [19].

Crowell [12] suggested that because species richness varies directly with area, absolute extinction will increase with area, while relative extinction will decrease with area. Actually, absolute extinction of tenebrionid species on the Aegean islands varied directly with area (as well as with other variables which correlate positively with richness such as elevation and perimeter), but percentage of extinct species was apparently not influenced by any island characteristics. This seems to contrast with the generalized idea that island populations are more prone to extinction because of the small area available and because they are more subject to demographic stochasticity and random climatic events (e.g. $[2,8])$. However, such factors are expected to influence equilibrial archipelagos. In non-equilibrial, relictual biotas, communities are composed of species which survived long time as the remains of ancient (and broader) faunas. These relict communities are not expected to be so profoundly subject to the present geographical factors which mould equilibrial faunas. Obviously, island characteristics, like area or elevation, may have exerted an important role in the process of relaxation after saturation during the late Pleistocene. But after this process ended, the relict faunas remained substantially unchanged until recent times. So profound changes in faunal composition like those which occurred in recent times on the Aegean Islands were not necessarily determined by island characteristics, but have to be referred to human activities which modified habitat characteristics (see $[14,15,18,19,25])$.

\section{CONCLUSIONS}

The Aegean Islands are an important biogeographic crossroad, where Balkan and Anatolian elements overlap (e.g. [21, 28]), making this archipelago of great biogeographic interest and one of the best studied in the Mediterranean (see [15,16,22,43-47], and references therein). It is, therefore, surprising that little attention has focused on potential threats to island biotas of this archipelago, the only two relevant researches involving a large number of animal species being those of Sfenthourakis and Legakis [15] and Troumbis and Dimitrakopoulos [14]. Sfenthourakis and Legakis [15] discussed in detail the importance of some Aegean Islands for endemic taxa of invertebrate groups like isopods, land snails, grasshoppers, carabid beetles and tenebrionid beetles. On the other hand, Troumbis and Dimitrakopoulos [14], using data for threatened birds, mammals and vascular plants, identified a number of 'threatspots', which overlap to a substantial degree with some island hotspots of invertebrates. Although these studies did not provide evidence of extinctions, it is likely that most of the threatened species disappeared or are near extinction. For tenebrionids several species were not recorded in recent time and have likely disappeared, at least from certain islands. Because humans continue to alter and fragment habitats, significant numbers of extinctions in the next few decades will continue to occur on islands. Thus, two problems arise: (1) to locate the islands which have, per se, a more exclusive or potentially threatened fauna; and (2) to determine the factors making these islands so 'vulnerable'.

Although analyses based on the presence of threatened or endemic species may represent an important tool, a more comprehensive approach should include an evaluation of community rarity from a multidimensional perspective. For these reasons, I attempted to rank the Aegean Islands under different measures of tenebrionid community rarity (geographic distribution, habitat exploitation, population size) searching for the possible factors (island geography and shape) underlying the patterns. 
In constructing a multidimensional representation of species rarity, in this study each species was scored with respect to geographic distribution, population size, and habitat exploitation. However, because of the lack of detailed data, estimates of population size and habitat exploitation were obtained from areal analysis. These measures were adopted as the best available approach to take into account different measures of rarity, but they should be considered with great caution as proxies of true values of species abundance and habitat specialization. It is important to assess if the three measures of species rarity used here can be interrelated simply due to little independence between calculation methods. Species with low population density could be undetected on islands where they actually occur because they are more difficult to be sampled than more abundant species. If abundant species are more likely to be detected, species density (calculated as contactability) and distribution measures could be correlated simply because of this detection problem. On the other hand, a species distributed on several islands should be easier to be collected. Thus, if the area occupied by each species is also going to determine its contactability, species with wider range could have higher contactability values. In fact, the Aegean tenebrionids include both species which are distributed in one or few islands, but that can be very abundant (and hence easily contacted) here (e.g. Asida fairmairei, Dendarus foraminosus, Pimelia minos, Probaticus euboeicus, Tentyria grossa grossa), and others which are distributed on several islands but rarely sampled (e.g. Akis elongata, Idastrandiella allardi, Nalassus plebejus, Probaticus tenebricosus).

Geographic distribution and potential habitat exploitation could be interrelated simply because species occurring on more islands are necessarily distributed over larger areas. However, the Aegean tenebrionids include both species distributed on several small islands (with large geographic distribution but small potential habitat exploitation, such as Dailognatha hellenica, D. quadricollis obtusangula, Eutagenia smyrnensis) and species distributed on few but large islands (with small geographic distribution and large potential habitat exploitation, such as Blaps cretensis, B. oertzeni, Cossyphus tauricus, Cylindronotus cretensis). Thus the measures of species rarity used here are not necessarily redundant, although they can be statistically correlated [25].

On the basis of the approach described in this paper, the Aegean tenebrionid fauna should be regarded as an assortment of communities of high conservation concern because of their irreplaceability, as a consequence of a relictual origin. This insular fauna (mostly composed of flightless species) originated by historical land-bridge connections, and present immigration is negligible because most of the species are unable to cross sea barriers $[19,21,33,40]$.

Thus, in contrast with equilibrial faunas, species extinctions cannot be compensated by new immigrants. Since present geography does not significantly influence this fauna [33], it is not surprising that the aforementioned measures of community rarity were scarcely affected by present island features.

This study clearly shows that the tenebrionid beetles on the Aegean Islands, one of the most important invertebrate component of the Aegean fauna in terms of species richness and levels of endemism $[15,18]$, constitute threatened faunal assemblages of great 'rarity' under several dimensions, and some islands are especially rich in rare species, deserving further attention in conservation efforts.

Although rarity analyses such as those developed here may provide useful insights into conservation actions, rarity per se is only one factor which may predispose a species to extinction. For conservation purposes, other factors, like proximity to locations of high human density, certain lifehistory traits like low reproductive rate, geographic location, and high trophic level may predispose a species to high extinction risk [29] and, therefore, could be considered in addition to rarity measures. However, rarity analyses such as those discussed here, may be a first step to identify communities on which further research should be focussed.

\section{ACKNOWLEDGEMENTS}

I am grateful to R.L.H. Dennis (NERC Centre for Ecology and Hydrology, Monks Wood, Abbots Ripton, Huntingdon, Cambridgeshire, UK) and A.P. Fowles (Countryside Council for Wales, Bangor, UK) for helpful discussions and suggestions. M.E. Hobbelink and S.S. Waters kindly improved the English.

\section{SUPPLEMENTARY MATERIAL}

The following material is available from
http://www.bentham.org

\section{Appendix S1}

Composition of the tenebrionid fauna and geographic and shape parameters for each of the 32 evaluated Aegean Islands. This matrix includes all variables used in the analyses.

\section{Appendix S2}

Species distribution among islands. This matrix reports species presence/ absence in the study islands.

\section{Appendix S3}

Species persistence. This matrix reports records of species per decade.

\section{REFERENCES}

[1] Lomolino MV, Perault DR. Island biogeography and landscape ecology of mammals inhabiting fragmented, temperate rain forests. Global Ecol Biogeogr 2001; 10: 113-32.

[2] Cook JA, MacDonald SO. Should endemism be a focus of conservation efforts along the North Pacific Coast of North America? Biol Conserv 2001; 97: 207-13.

[3] Frankham R. Inbreeding and extinction: island populations. Conserv Biol 1998; 12: 665-75.

[4] Blackburn TM, Cassey P, Duncan RP. Extinction in island endemic birds reconsidered. Ecography 2004; 27: 124-8.

[5] Morey M, Martínez-Taberner A. In: Trabaud L, Ed. Life and environment in the Mediterranean. Southampton: WIT Press, 2000; 345-86.

[6] Sadler JP. Biodiversity on oceanic islands: a paleoecological assessment. J Biogeogr 1999; 26, 75-87.

[7] Cowie RH, Robinson AC. The decline of native Pacific island faunas: changes in status of the land snails of Samoa through the $20^{\text {th }}$ century. Biol Conserv 2003, 110: 55-65.

[8] Hanski I. Population dynamics of shrews on small islands accord with the equilibrium model. Biol J Linn Soc 1986; 28: 23-36.

[9] Brook TMS, Pimm SL, Ng PKL. Catastrophic extinctions follow deforestation in Singapore. Nature 2003; 424: 420-426.

[10] Ulrich W, Buszko J. Habitat reduction and patterns of species loss. Basic Appl Ecol 2004; 5: 231-40. 
[11] MacArthur RH, Wilson EO. The theory of island biogeography. Princeton, Princeton University Press, 1967.

[12] Crowell KL. A comparison of relict versus equilibrium models for insular mammals of the Gulf of Maine. Biol J Linn Soc 1986; 28, 37-64.

[13] Médail F, Quézel P. Biodiversity hotspots in the Mediterranean Basin: setting global conservation priorities. Conserv Biol 1999; 13: $1510-13$

[14] Troumbis AY, Dimitrakopoulos PG. Geographic coincidence of diversity threatspots for three taxa and conservation planning in Greece. Biol Conserv 1988; 84: 1-6.

[15] Sfenthourakis S, Legakis A. Hotspots of endemic terrestrial invertebrates in southern Greece. Biodivers Conserv 2001; 10, 1387 417.

[16] Fattorini S. A new method to identify important conservation areas applied to the butterflies of the Aegean Islands (Greece). Anim Conserv 2006; 9:75-83.

[17] Cameron RAD, Mylonas M, Vardinoyannis K. Local and regional diversity in some Aegean land snail faunas. J Moll Stud 2000; 66: 131-42.

[18] Fattorini S. In: Fattorini S, Ed. Insect Ecology and Conservation. Trivandrum, Kerala: Research Signpost, in press

[19] Fattorini S. Biogeography and conservation of endemic tenebrionid beetles (Coleoptera Tenebrionidae) on East Mediterranean islands. Vie Milieu 2006; 56: 231-241

[20] Fattorini S. Levels of endemism are not necessarily biased by the co-presence of species with different range sizes: a case study of Vilenkin \& Chikatunov's models. J Biogeogr 2007; 34: 994-1007

[21] Fattorini S. Biogeography of the tenebrionid beetles (Coleoptera, Tenebrionidae) on the Aegean Islands (Greece). J Biogeogr 2002; 29: 49-67.

[22] Fattorini S. Fowles AP. A biogeographical analysis of the tenebrionid beetles (Coleoptera, Tenebrionidae) of the island of Thasos in the context of the Aegean Islands (Greece). J Nat Hist 2005; 39 (46): 3919-49.

[23] Fattorini S. Non-randomness in the species-area relationship: testing the underlying mechanisms. Oikos 2007; 116: 678-89.

[24] Fattorini S. Detecting biodiversity hotspots by species-area relationships: a case study of Mediterranean beetles. Conserv Biol 2006; 20: 1169-80.

[25] Fattorini S. A multidimensional characterization of rarity applied to the Aegean tenebrionid beetles (Coleoptera Tenebrionidae). J Insect Conserv. in press

[26] Fattorini S. Spatial variations in rarity in the Aegean tenebrionid beetles (Coleoptera, Tenebrionidae). Fragmenta entomol 2007; 38(2): 227-49.

[27] Fattorini S. A statistical method for idiographic analyses in biogeographical research. Divers Distrib 2007; 13: 836-44.

[28] Dennis, RLH, Shreeve TG, Olivier A, Coutsis JG. Contemporary geography dominates butterfly diversity gradients within the Ae- gean archipelago (Lepidoptera: Papilionoidea, Hesperoidea). J Biogeogr 2000; 27: 1365-83.

[29] Manne LL, Pimm SL. Beyond eight forms of rarity: which species are threatened and which will be next? Anim Conserv 2001; 4 221-29.

[30] Kattan G. Rarity and vulnerability: the birds of the Cordillera Central of Colombia. Conserv Biol 1992; 6: 64-70.

[31] Emerson B, Kolm N. Species diversity can drive speciation. Nature 2005; 434: 1015-17.

[32] Dapporto L, Dennis R. Species richness, rarity and Endemicity on Italian offshore islands: complementary signals from islandfocused and species-focused analyses. J Biogeogr 2007; in press.

[33] Fattorini S. Spatial patterns of diversity in the tenebrionid beetles (Coleoptera Tenebrionidae) of the Aegean Islands (Greece). Evol Ecol Res 2006; 8: 237-63.

[34] Legendere P. Spatial autocorrelation: trouble or new paradigm? Ecology 1993; 74: 1659-73.

[35] Borcard D, Legendre P. SpaceMaker 2. 2004. Available from http://www.bio.umontreal.ca/Casgrain /en/labo/spacemaker.html

[36] Legendre P., Legendre L. Numerical ecology, $2^{\text {nd }}$ English ed., Amsterdam, Elsevier Science BV, 1998

[37] StatSoft, Inc. STATISTICA (data analysis software system) version 6, 2001 .

[38] Systat Software, Inc. SigmaPlot for Windows v.10.0, 2006

[39] Moran MD. Arguments for rejecting the sequential Bonferroni in ecological studies. Oikos 2003; 100: 403-5.

[40] Fattorini S. Relict versus dynamic models for tenebrionid beetles of Aegean Islands (Greece) (Coleoptera: Tenebrionidae). Belg J Zool 2002; 132, 55-64.

[41] Fattorini S. A simple method to fit geometric series and broken stick models in community ecology and island biogeography. Acta Oecol 2005; 28: 199-205.

[42] Simberloff D. Design of wildlife refuges: what can island biogeographic principles tell us? Biol Gallo Hell 1986; 12: 19-42.

[43] Foufopoulos J, Ives AR. Reptile extinctions on land-bridge islands: life-history attributes and vulnerability to extinction. Am Nat 19991; 153:1-25

[44] Welter-Schultes FW. Spatial variations in Albinaria terebra land snail morphology in Crete (Pulmonata: Clausilidae): constraints for older and younger colonizations? Paleobiology 2001; 27: 348-68.

[45] Triantis KA, Mylonas M, Weiser MD, Lika K, Vardinoyannis K. Species richness, environmental heterogeneity and area: a case study based on land snails in Skyros archipelago (Aegean Sea, Greece). J Biogeogr 2005; 32: 1727-35.

[46] Panitsa M, Tzanoudakis D, Triantis KA, Sfenthourakis S. Patterns of species richness on very small islands: the plants of the Aegean archipelago. J Biogeogr 2006; 33: 1223-34.

[47] Fattorini S. Testing the latitudinal gradient: a narrow scale analysis of tenebrionid richness (Coleoptera, Tenebrionidae) in the Aegean archipelago (Greece). Ital J Zool 2006; 73 (3): 203-11

Received: March 12, $2008 \quad$ Revised: April 07, $2008 \quad$ Accepted: April 22, 2008

(c) Simone Fattorini; Licensee Bentham Open.

This is an open access article distributed under the terms of the Creative Commons Attribution License (http://creativecommons.org/license/by/2.5/), which permits unrestrictive use, distribution, and reproduction in any medium, provided the original work is properly cited. 